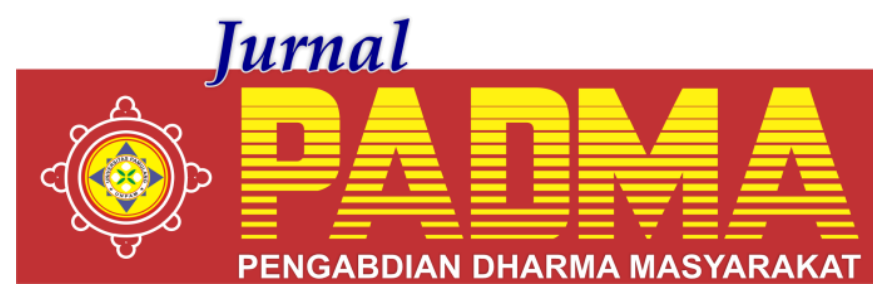

VOLUME 1, NOMOR I, JANUARI 2021

\title{
PENYULUHAN PENGELOLAAN KEUANGAN SEDERHANA SISWA SMK MUHAMMADIYAH PARUNG
}

\author{
${ }^{1 *}$ Agus Sudarsono, ${ }^{2}$ Hadi Winata, ${ }^{3}$ Hastono, ${ }^{4}$ Aden Prawiro Sudarso, ${ }^{5}$ Lucia Maduningtias \\ Universitas Pamulang, Tangerang Selatan, Banten, Indonesia \\ *dosen02473@unpam.ac.id
}

\begin{abstract}
Abstrak
Pengelolaan Keuangan Sederhana sebagai bentuk kepedulian dan pengabdian kepada masyarakat kepada Siswa SMK Muhammadiyah Parung sangat tepat untuk dilaksanakan. Kebutuhan manusia dalam ilmu ekonomi bisa dikatakan tidak terbatas adanya. Semua keinginan ingin sekali terealisasi dengan mudah. Kondisi ini tentusaja tidak akan bisa terwujud tanpa adanya pengaturan keuangan yang baik. Dalam kegiatan ini metode yang diterapkan diharapkan dapat memberikan kemudahan kepada para mahasiswa SMK Muhammadiyah Parung. Metode yang digunakan adalah metode diskusi kelompok, sharing, tanyajawab, praktik yang di damping oleh pemateri. Pada metode penjelasan, setiap instruktur menyampaikan materi terkait dan membuat tampilan visual berupa slide power point yang ditampilkan ke layar dengan LCD proyektor. Hasil kegiatan adalah mereka dapat melakukannya sendiri di rumah. Siswa dapat mendapatkan ilmu pengetahuan baru, sehingga bisa dimaksimalkan potensi diri dengan cermat dan hemat.
\end{abstract}

Kata Kunci: Keuangan Sederhana

Abstract

Simple Financial Management as a form of concern and community service to Muhammadiyah Vocational School Parung Students is very appropriate to be implemented. Human needs in economics can be said to be unlimited. All wishes long to be realized easily. This condition certainly would not have been possible without good financial arrangements. In this activity the method applied is expected to provide convenience to students of Muhammadiyah Vocational School Parung. The method used is the method of group discussion, sharing, question and answer, practice accompanied by the speaker. In the explanation method, each instructor conveys related material and makes a visual display in the form of a power point slide that is displayed on the screen with the projector's LCD. The result of the activity is that they can do it themselves at home. Students can get new knowledge, so they can maximize their potential with care and efficiency.

Keywords: Simple Finance

\section{PENDAHULUAN}

SMK Muhammadiyah Parung memiliki nama baik yang cukup bagus di mata masyarakat. Salah satu sekolah unggulan yang ada di Kab Bogor, SMK Muhammadiyah selalu berupaya mencetak lulusan yang tidak hanya cakap dalam bidang akademis dan non akademis, tetapi juga memiliki karakter yang siap bersaing dalam secara intelektual.

Beberapa Siswa Smk Muhammadiyah memiliki minat berwirausaha yang tinggi. Hal itu ditunjukkan dengan kegiatan wirausaha yang dilakuakan di lingkungan sekolah. Menjadi reseller, drop shiper atau bahkan endorser, baik untuk produk orang lain ataupun produk buatan sendiri. Fenomena tersebut menimbulkan budaya berwirausaha di lingkungan sekolah. Sayangnya mayoritas siswa berwirausaha dengan kemampuan skill yang terbatas, sehingga baik pengalaman maupun profit yang didapatkan oleh mereka kebanyakan masih belum maksimal. Beberpa diantaranya masih kurangnya pemahaman dan pengetahuan para remaja khususnya siswa dalam mengelola keuangan mandiri, siswa yang memiliki kegiatan usaha dalam hal mengatur diri dan membuat perencanaan keuangan yang baik. Hal itu dikarenakan para siswa mayoritas masih belum memiliki pemahaman dan sikap dalam mengelola keuangan yang baik.

Sebagai salah satu SMK Unggulan di Kab Bogor, SMK Muhammadiyah Parung 
berkewajiban membentuk mindset dan ketrampilan peserta didiknya agar mampu bersaing di era siswa saat ini. Salah satunya adalah dengan mengembangkan skill kewirausahaan para siswa. Agar Siswa dapat memiliki semangat berwirausaha yang terstruktur sejak dini, mampu memetakan diri dan dapat membuat branding diri dan produk yang dibuat.

Identifikasi masalah yang ditemukan di lapangan adalah masih banyak siswa merasakan tekanan dalam finansial untuk saat ini dan masa depan. Lebih dari seperempat, atau sekitar 28 persen merasakan banyak kecemasan finansial sehingga berdampak dari kegiatan belajar yang sedang dijalani. Masalah keuangan membuat siswa mengalami stress dan memikirkannya terus-menerus, pola hidup konsumtif pada usaia remaja akan berdampak buruk juga dengan keuangan mereka . Dengan kecemasan yang berlebih, besar kemungkinan siswa malah mengambil keputusan yang salah. Seperti tidak sengaja menghabiskan uang. Ditemukan masih kurangnya pemahaman dan pengetahuan para remaja khususnya siswa dalam mengelola keuangan mandiri, siswa yang memiliki kegiatan usaha dalam hal mengatur diri dan membuat perencanaan keuangan yang baik. Hal itu dikarenakan para anggota mayoritas masih belum memiliki pemahaman dan sikap dalam berorganisasi yang baik. Sehingga diperlukan penyuluhan mengenai pengelolaan keuangan sederhana. Agar siswa dapat megelola keuangan dengan baik, hal itu akan sangat membantu ketika seseorang yang menginjak masa dewasa awal, masa di mana secara psikologis jiwanya masih rentan untuk terpengaruh dan mudah berubahubah, hal utama yang menjadi konstentrasi adalah keuangan bagi para dewasa awal.Mengingat pengeluarannya juga akan besar karena gaya hidup pada masa ini lebih tinggi daripada anak-anak atau orang tua. Remaja yang berada pada masa ini mendapatkan pemasukan dari orang tua atau hasil mengelola keuangan. Sehingga harus dapat memanage keuangannnya dengan baik.

Masalah keuangan yang dihadapi siswa adalah pengeluaran lebih besar dibandingkan dengan uang bulanan yang didapat dari orangtua.Sebagai seorang siswa, sudah harus mulai melatih diri untuk bisa mandiri dan bisa mengatur keuangan sendiri tanpa campur tangan orangtua.Akan tetapi, masih banyak siswa yang kehabisan uang jajan sampai harus menahan lapar di akhir bulan. Uang bulanan pemberian orang tua seringkali tidak bisa mencukupi semua kebutuhan dan memaksa siswa untuk mencari cara (biasanya pinjam uang ke teman) demi bertahan hingga bulan berikutnya. Siswa sangat konsumtif dalam berbelanjan, Tawaran diskon, apalagi dengan skema "potongan pada pembelian kesekian" mendorong seseorang untuk membeli barang-barang yang kurang esensial demi mengejar diskon. Alasannya, "suatu saat akan berguna" atau "kapan lagi dapat barang murah". Padahal setelah dihitung benarbenar-misalnya pada barang " $A$ "-, perbedaan harga setelah mendapatkan diskon dengan sebelum diskon hanya berbeda sedikit saat membelinya satuan. Siswa seharusnya dapat belajar untukk lebij realistis pada jebakan-jebakan diskon yang ditawarkan. Tak lagi menjadi kalap, siswa akan lebih selektif pada barang yang benarbenar esensial, dengan atau tanpa diskon. Agar hal tersebut tidak terjadi, siswa perlu membuat anggaran keuangan dan disiplin mencatat keuangan setiap bulannya.

Sebagian siswa masih berpikir bahwa kegiatan mereka hanya sekadar belajar dan berpartisipasi dalam kegiatan sekolah yang tidak bisa menghasilkan uang. Masalah keuangan siswa berikutnya adalah susahnya untuk menabung dan melakukan investasi dengan uang jajan bulanan. Dengan status siswa yang dimiliki terkadang membuat siswa berpikir santai dan merasa masih punya banyak waktu untuk mempersiapkan masa depan sehingga merasa tidak perlu rajin menabung. Padahal kebiasaan dari usia muda inilah yang akan menentukan kesuksesan financial mereka saat dewasa nanti.

Masalah keuangan siswa selanjutnya adalah tidak memiliki uang di saat-saat genting.Misalnya, tiba-tiba guru mewajibkan seluruh siswa untuk membeli peralatan praktikum yang mahal. Atau tiba-tiba siswa jatuh sakit dan harus dirawat, sementara tidak punya uang yang cukup. Setiap orang tentu akan/telah melewati masa dewasa 
awal atau masa peralihan dari masa remaja. Masa dewasa awal terjadi saat usia kurang lebih 20 tahun. Saat memasuki masa tersebut, seseorang sudah mulai menemukan identitas dirinya. Banyak hal yang harus dipersiapkan seseorang untuk mmempersiapkan masa ini.

Berbagai macam perubahan juga terjadi pada diri seseorang yang sedang menginjak masa ini. Mulai dari perubahan fisik, mental, pola pikir, dan lainnya. Salah satu yang terjadi pada masa ini yaitu rasa ketergantungan akan berkurang dan berubah menjadi rasa mandiri. Perasaan untuk memiliki kebebasan menjalani kehidupan sendiri akan muncul. PSiswangan mengenai masa depan pun akan berubah menjadi lebih realistis. Masa-masa ini menjadi salah satu masa paling krusial bagi setiap orang. Selain perubahan, banyak pula masalah mulai muncul seiring bertambahnya usia. Rasa mandiri dan perasaan ingin memiliki kebebasan menjadi salah satu hal yang harus diwaspadai dan mendapat perhatian lebih dari orang tua. Hal itu dapat terjadi pada semua bidang, salah satunya adalah mengenai keuangan. Kemampuan dalam mengelola keuangan setiap orang berbeda-beda. Beberapa ada yang memiliki kemampuan mengelola keuangan dengan baik, sisanya tidak. Padahal keuangan merupakan hal penting untuk melakukan aktifitas khususnya yang berhubungan dengan kegiatan jual beli.

\section{Masyarakat \\ Manfaat Pengabdian Keapda \\ Kegiatan Pengabdian Kepada Kegiatan} Pengabdian Kepada Masyarakat dari tim dosen dan mahasiswa Universitas Pamulang hadir di SMK Muhammadiyah Parung dalam bentuk pelatihan. Pelatihan ini akan melakukan pendekatan kekinian dengan metode diskusi berkelompok sehingga dapat lebih mudah dipahami oleh siswa SMK Muhammadiyah Parung yang rata-rata adalah pemuda dan remaja siswa yang up to date dengan keadaan saat ini. Beberapa materi pengelolaan keuangan, khususnya untuk siswa yang mendapatkan uang dari pekerjaan sampingan bisa menjadi langkah awal yang tepat untuk dilaksanakan oleh remaja menuju kemandirian ataupun kebebasan finansial atau financial freedom. Hal ini tentu akan bisa didapatkan pada saat sang anak ataupun remaja telah lulus kuliah dan mendapat pekerjaan, atau justru sudah memiliki kehendak mengelola keuangan sambilan (part time) saat masih sekolah pun kuliah.

Uang yang diterima sebagai upah mengelola keuangan itu apabila dikelola dengan baik sangat memberi arti, dapat menjadi peranan penting dalam pembentukan jati diri anak guna mempersiapkannya di masa mendatang. Sangat diharapkan dari pelatihan ini para siswa di Smk Muhammadiyah dapat mengelola keuangannya degan cara yang sederhana, dan dapat membentuk karakter hemat dan bijak dalam mengelola keuangan.

\section{METODE}

Dalam kegiatan ini metode yang diterapkan diharapkan dapat memberikan kemudahan kepada para mahasiswa SMA 6 Tangerang Selatan. Metode yang digunakan adalah metode diskusi kelompok, sharing, tanyajawab, praktik yang di damping oleh pemateri. Pada metode penjelasan, setiap instruktur menyampaikan materi terkait dan membuat tampilan visual berupa slide power point yang ditampilkan ke layar dengan LCD proyektor.

Instruktur dalam menyampaikan penjelasan juga memasukkan unsur "sharing" atau berbagi pengalaman mengenai pengelolaan binis sederhana yang dilakukan oleh siswa dan materi yang telah dimiliki pemateri, dengan pertimbangan tersebut diharapkan dapat memberikan gambaran lebih jelas kepada peserta. Pada metode praktik, peserta berkelompok dan dengan pendampingan panitia mahasiswa bergantian menyusun perencanaan binis secara bergantian berkaitan dengan temannya. Peserta diajarkan bagaiman acara menyusun daftar kebutuhan dan mereka diperbolehkan memberikan penambahan daftar keinginan yang ingin mereka capai beserta strategi untuk mencapainya. Dengan demikian siswa tidak hanya sekedarterarah, dengan menggunakan pengelolaan binis sederhana yang jelas.

\section{HASIL DAN PEMBAHASAN}

\begin{tabular}{lrr}
\multicolumn{1}{c}{ Kegiatan } & Pengabdian & Kepada \\
Masyarakat ini & berkaitan & erat \\
dengan pengelolaan & keuangan pada & siswa.
\end{tabular}


Pemahaman akan pentingnya uang haruslah disadari oleh usia remaja, dan sekolah menengah harus bisa membimbing setiap pelajar untuk dapat memahami keuangan dengan baik. Fokus utama dalam aktivitas pengelolaan keuangan memang harusnya disebar secara tersirat dalam mata pelajaran ekonomi dan akuntansi. Hal itu haruslah didasarkan pada intensitas perencanaan, kesiapan berpartisipasi dalam kehidupan sebagai pribadi yang independent, dan keterarahan individu-individu kepada tujuan. Masalah pengelolaan keuangan siswa di SMA dan SMK lebih mengacu pada hal-hal berikut:

Psikologis Kaula Muda yang Umumnya Senang Hura-Hura. Tak bisa dipungkiri, anak muda memang senang menghabiskan waktu untuk berkumpul/ nongkrong, menikmati sesuatu yang sedang tren, berusaha untuk terus sejalan dengan perkembangan terkini dalam berbagai bidang, dan sebagainya. Apalagi bagi siswa yang belum memiliki tanggungan atau masih lajang. Karena belum memiliki tanggungan, ia merasa belum bertanggung jawab untuk mengelola keuangannya karena pendapatannya hanya untuknya. Jadi, anggapan bahwa penghasilannya hanya untuknya seakan melekat dalam dirinya.

Tidak Mempersiapkan Dana Darurat Sehingga Kebingungan Saat Keperluan Mendadak Muncul. Dana darurat tidak hanya permasalahan yang harus dipersiapkan oleh orang akan sangat bermanfaat bila nantinya ada saja ke dewasa. Siswapun memerlukan ini untuk membayar perluan mendadak yang harus dipenuhi sementara uang Siswa tidak cukup untuk menutupinya. Siswa mungkin belum terpikir untuk mempersiapkan dana darurat, atau bila pun sudah terpikir, uang Siswa sudah habis lebih dulu sebelum benarbenar memulai untuk menyiapkan dana darurat. Solusinya dari sekarang Siswa harus bisa menyisihkan sejumlah uang yang kemudian dialokasikan khusus untuk dana darurat. Misalnya, dalam sebulan, cobalah sisihkan uang saku Siswa per bulan, misalnya 20\% dari gaji Siswa, khusus untuk dana darurat. Nantinya, jangan pernah sentuh uang tersebut selain dari keperluan mendesak.

Tidak Menabung Sehingga Kebutuhan Jangka Panjang Susah Dipenuhi. Menabung juga menjadi salah satu cara mengelola dan membentuk tujuan euangan yang baik. Katakanlah Siswa berencana menikah di usia 28 tahun. Bila Siswa sudah merencanakan hal tersebut maka Siswa juga harus mempersiapkan keuangan untuk biaya pernikahan. Kecuali bila ada donatur yang membiayai atau pernikahan Siswa disponsori. Bila tidak ada, maka mulailah menabung. Paksa diri Siswa untuk memulai, dan biasakan agar tetap konsisten seturut waktu.

Tidak Berinvestasi Sehingga Keuangan Habis Begitu Saja Tidak Menghasilkan. Salah satu masalah keuangan yang sering dihadapi Siswa adalah kurangnya kesadaran bahwa seturut waktu uang yang ia miliki akan berkurang nilainya terutama ketika inflasi terjadi. Setiap Siswa kerap mengabaikan fakta bahwa pendapatan hari esok bisa saja lebih rendah ketimbang hari ini. Maka dari itu demi mempersiapkan diri dari kemungkinan-kemungkinan yang menyesakkan ke depannya, jangan biarkan uang yang Siswa miliki saat ini diam tak menghasilkan. Siswa bisa mencari sumber penghasilan baru seperti berbisnis atau memulai pekerjaan sampingan. Siswa bahkan bisa berinvestasi terutama karena beragam instrumen investasi.

\section{PENUTUP}

Hasil kegiatan PKM di SMK Muhammadiyah Parung berjalan dengan lancar. Siswa terlihat antusias mempelajari materi dalam kegiatan PKM Penyuluhan pengelolaan keuangan sederhana, Selain itu metide menabung juga memberikan pemahaman baru kepada siswa dalam melakukan pengelolaan keuangan tidak harus selalu dengan nominal uang yang besar, atau instrument yang rumit. Mereka dapat melakukannya sendiri di rumah. Siswa dapat mendapatkan ilmu pengetahuan baru, sehingga bisa dimaksimalkan potensi diri dengan cermat dan hemat.

\section{DAFTAR PUSTAKA}

Amelia, R. W., \& Sunarsi, D. (2020). Pengaruh Return On Asset Dan Return On Equity Terhadap Debt To Equity Ratio Pada PT. Kalbe Farma, TBK. Ad Deenar: Jurnal Ekonomi dan Bisnis Islam, 4(01), 105-114. 
Dewi, R. V. K., Sunarsi, D., \& Akbar, I. R. (2020). Dampak Penggunaan Teknologi Informasi dan Komunikasi Terhadap Minat Belajar Siswa di SMK Ganesa Satria Depok. Jurnal Ilmiah Wahana Pendidikan, 6(4), 1001-1007.

Hermawati, R., Sugiyarti, L., Handayani, R., Sunarsi, D., Alfiah, S., \& Maddinsyah, A. (2020). The Effect of Trilogy Leadership Style and Organization Culture on School Performance: Evidence form Indonesian Senior High School. PalArch's Journal of Archaeology of Egypt/Egyptology, 17(6), 8512-8537.

Hidayat, A., \& Sunarsi, D. (2020). FaktorFaktor Yang Mempengaruhi Dana Pihak Ketiga Dan Dampaknya Terhadap Profitabilitas (Survey Pada Bpr Syariah Di Jawa Barat Tahun 2014-2017). Jurnal Proaksi, 7(1), 5465.

K Nufus, H Supratikta, A Muchtar, D Sunarsi. (2020). Analysis of Financial Performance: Case Study of PT. X Employee Cooperative. Utopía Y Praxis Latinoamericana. Vol. 25. Pages 429444

Maddinsyah, A., Hidayat, D., Juhaeri, J., Susanto, D., \& Sunarsi, D. (2020). Desain Formulasi Dan Implementasi Bisnis Strategik Dengan Pendekatan Business Model Canvas (BMC) Terintegrasi Kerangka Integrated Performance Management System (IPMS) Pada Koperasi Asperindo. Inovasi, 7(2), 67-76.

Manajemen Keuangan Untuk Siswa SMA 1 https://goo.gl/C3B1hJ

Manajemen Keuangan Untuk Siswa SMA 2 https://goo.gl/1NkaE2

MirSiswa Marquit. 10 April 2017. Essential Financial Skills to Learn Your Senior Year of High School. Discover.com https://goo.gl/HnNxY7

Nofiana, L., \& Sunarsi, D. (2020). The Influence of Inventory Round Ratio and Activities Round Ratio of Profitability (ROI). JASa (Jurnal Akuntansi, Audit dan Sistem Informasi Akuntansi), 4(1), 95-103.

Noryani, Y. B. G., Sari, W. I., Rosini, I., Munadjat, B., Sunarsi, D., \& Mahnun Mas' adi, G. (2020). Did ISO 45001, ISO 22000, ISO 14001 and ISO 9001 Influence Financial Performance? Evidence from Indonesian Industries. PalArch's Journal of Archaeology of Egypt/Egyptology, 17(7), 6930-6950.

Noviyanti, I., Hayati, F. A., Nufus, K., Maduningtias, L., Rostikawati, D., Sunarsi, D., \& Effendy, A. A. (2020). Did Virtual Transformational Leadership Style Influence Schools Performance? Answer form Indonesian Senior High Schools. PalArch's Journal of Archaeology of Egypt/Egyptology, 17(6), 8438-8461.

Paeno, P., Kasmad, K., Sunarsi, D., Maddinsyah, A., \& Supiyan, D. (2020). Pemanfaatan Sampah Plastik Untuk Kerajinan Rumah Tangga Taman Belajar Kreatif Mekar Sari. Baktimas: Jurnal Pengabdian pada Masyarakat, 2(1), 57-61.

Susanti, N., Latifa, I., \& Sunarsi, D. (2020). The Effects of Profitability, Leverage, and Liquidity on Financial Distress on Retail Companies Listed on Indonesian Stock Exchange. Jurnal Ilmiah Ilmu Administrasi Publik, 10(1), 45-52.

Sutrisno, S., Abidin, A. Z., Winata, H., Harjianto, P., \& Sunarsi, D. (2020). Penyuluhan Pengelolaan Keuangan Sederhana Siswa SMA 6 Tangerang Selatan. BAKTIMAS: Jurnal Pengabdian pada Masyarakat, 2(1), 67-71.

Yusni Nuryani, Denok Sunarsi. (2020). The Effect of Current Ratio and Debt to Equity Ratio on Deviding Growth. JASa (Jurnal Akuntansi, Audit dan Sistem Informasi Akuntansi) Volume 4, Issue 2, Pages

304-312. 